\title{
Teaching microbiology in times of plague
}

\author{
Manuel Sánchez-Angulo ${ }^{1} \mathbb{D} \cdot$ Ignacio López-Goñi ${ }^{2} \cdot$ Víctor J. Cid $^{3}$
}

Received: 30 March 2021 / Revised: 21 April 2021 / Accepted: 23 April 2021 / Published online: 3 May 2021

(c) The Author(s), under exclusive licence to Springer Nature Switzerland AG 2021

\begin{abstract}
The COVID-19 pandemic has imposed several challenges and strains at all levels of the educational system, especially as a consequence of lockdown and social distance measures. After a period of exclusive use of the online educational environment, educators have adapted to the new circumstances and, by a combination of different strategies, have fought to overcome the limitations and deficiencies of virtual learning. Student motivation, productivity, and creativity continue to be the main pedagogical issues that have to be reached with the new didactic tools developed during the pandemic. At the same time, this pandemic has shown the importance of the inclusion of microbiology as a core element of the educational curriculum and the opportunity to raise public awareness of the importance of microbes to everyday life.
\end{abstract}

Keywords Science communication · Social networks · Microbiology education · Active learning · Virtual learning · Service learning

\section{Introduction}

In the year 2004, the American Society for Microbiology published a report with the title "Microbiology in the $21^{\text {st }}$ Century. Where are we and where are we going?" (ASM 2004). The report summarizes the discussions held by the members of the American Academy of Microbiology about the future directions to be taken by microbiologists regarding different subjects, such as research challenges, the impact of microbes at a planetary scale, microbial literacy in society, and, of course, the essential issue of the presence of microbiology in the educational curricula. Some of the recommendations read as follows:

- Teaching microbiology should be thoroughly integrated into school curricula.

Manuel Sánchez-Angulo

m.sanchez@umh.es

1 Departamento de Producción Vegetal y Microbiología, Edificio Torrepinet, Universidad Miguel Hernández, 03202 Elche, Spain

2 Departamento de Microbiología y Parasitología, Universidad de Navarra, 31008 Pamplona, Spain

3 Departamento de Microbiología y Parasitología, Facultad de Farmacia, Universidad Complutense de Madrid, \& Instituto Ramón y Cajal de Investigaciones Sanitarias (IRyCIS), Pza. Ramón y Cajal s/n 28040, Madrid, Spain
- General biology texts should be organized around a microbiology core.

- All life scientists should receive microbiology training as part of their core curriculum.

- Building an understanding of microbes in young students will ultimately improve public awareness of the importance of microbes to the everyday health of the individual and of the planet.

Although the report was addressed to the politicians and other decision-makers in the USA, their recommendations could indeed be applied to other countries. Fifteen years later, it seemed that the suggestions made by the ASM had little impact, as testified by the editorial "The urgent need for Microbiology literacy in society" published in the Environmental Microbiology journal, and signed by several microbiologists (Timmis et al. 2019). In that editorial, the following statement was again put forward: Microbiology must become a core element of the school curriculum in order that decision makers are adequately informed.

But things have changed since March 2020 dragged by the COVID-19 pandemic. A Spanish proverb says "they hang people by force" (needs must when the devil drives), and overnight, the whole society of many countries was eager for explanations about the threat represented by the emerging virus. Immediately, several scientists from different fields, ranging from microbiology to epidemiology, were 
interviewed in the media. Also, the epidemic situation hits hard in the educational field. In many countries, face-to-face teaching had to be changed to virtual learning from one day to the next in all the educational levels. Of course, the new situation was not only stressful but also added additional strains on the system such as the adaptation of teaching material to virtual platforms or the speed of internet connection from homes. Paraphrasing the saying, by a cocktail of bytes, toil, tears and sweat, the situation was saved, although it claimed its toll. A recent survey in the USA showed that the number of faculty members that felt stressed in 2020 doubled the figures of 2019 (Gewin 2021). Currently, we are in the umpteenth pandemic wave, and vaccination is unhurriedly at hand in most countries so virtual teaching prevails, but now we have more experience and tools. In fact, as it happened with other crises in history, a tough time is a time for opportunities.

\section{Virtual learning, the comeback of the didactic lecture}

In the last two decades, there has been a shift from didactic lectures towards what is termed active, or even authentic, learning. According to Bonwell and Eison (1991), "active learning" encompasses any pedagogic method that involves students in actually doing things, and subsequently reflecting about the things they are doing. This is a wide definition, which covers diverse contexts, such as class debates over hot topics in the news, problem-based activities, and conducting real-life experiments in the laboratory. Although active learning clearly increased student performance in Science subjects (Freeman et al. 2014), the shift to active learning has been linked to the erroneous thought that the traditional didactic lecture is less effective as a teaching tool due to its passive nature, overlooking that the key element of learning is the engagement of the student (Richardson 2008; Zakrajsek 2018). Active learning suits very well teaching in the field of microbiology, as evidenced by crowdsourcing science projects such as Tiny Earth or gamification of class activities, as exposed below. But, most of such activities were halted by the lockdown caused by the SARS-CoV-2 pandemic. Overnight, teachers were forced by the circumstances to base all their lessons on didactic lectures, even those designed as laboratory training, with the added difficulty that the classes were performed online, lacking the "human touch." Thus, a huge effort has been devoted to reorganize the lectures and to enhance them by including virtual active learning activities within the virtual framework, with the aim of engaging the students. One could say that we have witnessed a comeback of the traditional didactic lecture but aided by twenty-first-century technology. In this scenario, it was critical to maintain student motivation and productivity. Some useful advice on how to confront such a situation, avoiding the feeling that the teacher was talking to a screen without knowing whether there was someone listening, interacting, or reacting, can be found in McReynolds et al. (2020). Paradoxically, one advantage of virtual meetings is that the risk that the other party can disconnect at any moment stimulates the productivity of the person who hosts the meeting. It is also important to take care of the user background, because it may influence the class atmosphere. The use of a template background reduces the risk that the other party loses their attention. Finally, it is recommended to use some non-academic virtual activities like playing games, perform informal introductions, or discuss a hot topic related to the subject to be learned.

It should be noted that several members of the Spanish Society of Microbiology (SEM) have a previous and long experience in the field of virtual teaching. Since 2010, the SEM has offered several online courses (Table 1). The courses are aimed to the training of specialized technical staff from the biotechnological sector, but graduates from diverse scientific areas take these courses in order to update their microbiology background as well. Each course is equivalent to 4 ECTS and they are imparted through the Moodle platform. Until now, almost a thousand students have enrolled in these courses, being the one dedicated to the Microbiology and Preservation of Cosmetics the most successful of all (García and Moreno 2020).

But Scientific Societies like SEM may also test several social media platforms in search for more interactive forms
Table 1 Online courses offered by the Spanish Society of Microbiology

\begin{tabular}{ll}
\hline Field of interest & Course name \\
\hline Clinical & $\begin{array}{l}\text { Control and Prevention of Emerging Viruses } \\
\text { Biosafety and Occupational Risk Prevention in Microbiologi- } \\
\text { cal Laboratories } \\
\text { Human Microbiome: Health Implications }\end{array}$ \\
Food and Agriculture & $\begin{array}{l}\text { Culture Independent Techniques applied to Food Microbiology } \\
\text { Biotechnology and Microbiological Food Safety } \\
\text { Environment }\end{array}$ \\
Pharmacy and Drugs & Microbiology and Preservation of Cosmetics \\
\hline
\end{tabular}


of communication to engage the public. Social networks have several advantages to scientists, such as promoting the research group or institution, improving communication skills, and promoting public engagement (López-Goñi and Sánchez-Angulo 2018). The most successful to date has been the use of Twitter, a microblogging social media platform where users can post short texts (tweets) that can be accompanied by images, short videos, or hyperlinks. Tweets can be replied to, retweeted, or mentioned by the use of hashtags, thus fostering interactivity among followers and creating a dynamic conversational platform amenable to the exchange of information. In 2016, \#microMOOCSEM, the first Massive Open Online Course (MOOC) dedicated to General Microbiology was launched by the SEM (LópezGoñi et al. 2017). Each lesson covered a particular topic such as microbial evolution, microbiome, vaccines, or antibiotic resistance, and was composed of 30 to 40 tweets. Each tweet was a "catch phrase" meant to communicate science to a general audience outside the academic environment associated to a link, a video, or an image illustrating the topic. The first two courses were broadcasted in Spanish, but after their success, the 2018 course was produced in English with the participation of the Federation of European Microbiology Societies (FEMS) and tagged \#EUROmicroMOOC. The course was imparted by Researchers and Professors from universities or research centers located in Spain, the USA, or the UK. The whole course was composed of 21 lessons and comprised a total of 738 tweets, 439 images, 74 videos, and 340 hyperlinks to websites related to microbiology (López-Goñi, et al. 2019). The \#EUROmicroMOOC course was repeated again in the year 2020 during the lockdown. All the lessons were compiled and can be reached through Wakelet (https://wakelet.com/@SEMicrobiologia).

\section{From the Small World Initiative to MicroMundo}

In the year 2012, Jo Handelsman and her team designed an innovative discovery-based educational project in order to motivate students towards STEM disciplines and to increase scientific literacy in society. The project was named Small World Initiative (SWI) and the idea, based on crowdsourcing in the academy, was to engage undergraduate students to perform field and laboratory tasks in a hunt for microorganisms that might potentially produce new antibiotics. In a collaborative and openly creative manner, the SWI experimental approach brought the student into a close understanding of Alexander Fleming's famous serendipitous discovery of penicillin, or - more accurately - to targeted search for antimicrobial bioactivities developed through the second half of the 20th century, after Waksman's discovery of streptomycin. The students are trained to collect, process, and analyze soil samples in the laboratory under the supervision of SWI Instructors. Upon completion of the project, the participating students and instructors have the opportunity to present their original research and share their findings in specific meetings (Hernandez et al. 2015). Recently, the former SWI team has launched an advanced program named Tiny Earth, which integrates basic microbiology with genomics and chemical analyses for a deeper characterization of the students' findings (Hernandez et al. 2018; Hurley et al. 2021).

The SWI program was transferred to different countries, such as the UK and Spain, where the Complutense University of Madrid led the way in 2016. As an innovation compared to the original North American project, the Spanish approach operated from the University but worked off-campus. Thus, it integrated two educational levels, secondary/ high school and the university, following a hierarchic strategy based on service-learning. The aim was to inspire and retain high school students in sciences through discoverybased research experiences (Valderrama et al. 2018). From Madrid, this educational project was extended and adopted by over 30 Spanish and Portuguese universities (Antunes et al. 2021, Maicas et al. 2020). Currently, the Spanish branch follows the path established by the Tiny Earth project and has been renamed "MicroMundo."

In the first symposium of the MicroMundo project, held in 2018, it was concluded that an added value of the project was its flexibility and adaptability to the creative spirit of the researchers, teachers, and students belonging to the different levels involved. The project has been evolving and adapting different pedagogical derivatives through the years for a better achievement of its goals. For example, to overcome one of the problems encountered, the fact that students were discouraged by the low proportion of antibiotic-producing microorganisms found in their soil samples, de Groot and coworkers modified the protocols in order to increase the isolation of Actinobacteria, the main producers of antibiotics. This contributed in their hands to optimize the educational efficiency of the program and to create a more stimulating educational atmosphere, rendering a more positive perception of the learning outcomes, according to the results obtained by the anonymous surveys after completion of the activity (de Groot et al. 2019).

Although the coronavirus pandemic supposed a sudden halt in all activities for the MicroMundo groups in 2020, according to the reports recently published in the SEM@foro Thematic Issue on Education (https://www.semicrobiologia. org/secciones/publicaciones/semaforo/69), several teams struggled to set the project in its tracks again with new strategies and approaches adapted to the virtual environment. The pandemic crisis has underlined the need for scientific education in subjects such as microbiology and other areas engulfed by the One Health concept. MicroMundo teams have seen an opportunity to bring together high schools 
and universities in a joint effort to develop strategies for the dissemination of global health issues related to microbiology, including emerging viruses and antibiotic resistance. A wealth of infographics, videos, games, social network activities, etc., are being devised by students to feed the virtual space with tools for microbiology education in Portuguese and Spanish. This effort should produce a wealth of free online tools ready to be used in Spain, Portugal, and Latin American countries.

\section{Learning technologies: solutions, problems, or both}

Currently, learning technologies are ubiquitous in Science degrees. Initially, they were implemented as a way to achieve a more effective teaching and active learning. But, through further development along the years, learning technologies have become a possible substitute for face-to-face teaching, anticipating that they will drive pedagogical advance, increase interactivity, and facilitate the mastery of essential capabilities. This viewpoint has been described as an example of solutionism, a form of oversimplistic thinking that assumes that only technologies by themselves can solve complex educational issues (Grainger et al. 2020). One example of solutionism is the actual claim that "we must teach/learn technological abilities because all the knowledge is one click ahead." Aside from the fact that in the sentence there is a confusion between "information" and "knowledge," most studies on technological solutions in Education yield no significant differences. In fact, the lockdown due to the coronavirus crisis has exposed the limitations and deficiencies of teaching and learning by exclusively using online methodologies.

To avoid solutionism, McKenney and Reeves (2020) have proposed the use of Educational Design Research (EDR) in the development of new theoretical insights and practical solutions to serious teaching and learning challenges. In EDR, there is a pursuit of practical and scientific goals by the iterative development of solutions to complex educational problems, thus providing the context for empirical investigation which will yield theoretical understanding. An example of an EDR approach is the project "MicroMundo" (see above), where a particular model of service-learning has been created in order to deal with a real-world challenge. In EDR, there are three core phases, the first one being the "analysis and exploration" of the problem to be addressede.g., antimicrobial resistance awareness. The second one is the "design and construction" of how the problem might be addressed-educational service-learning project. In the third phase, "evaluation and reflection" design ideas and solutions are empirically investigated and the findings are presented and discussed—students surveys and MicroMundo
Symposia-in order to refine the theoretical understanding of the problem.

\section{Pursuing motivation during confinement}

In her review about the contents of the last FEMS Thematic Issue "Learning for the future," Beatrix Fahnert made some interesting pre-pandemic thoughts about the skills to be acquired as a goal for 2020, highlighting "critical thinking," "creativity," and "judgement and decision-making" as essential to counteract fake news and develop openminded, resilient, adaptable, and ethical citizens (Fahnert 2019). According to what is called Education 4.0, teachers are facilitators who teach learners how to access, process, and evaluate the vast amount of knowledge and information available in the virtual space. In fact, before the pandemic, several universities were already laying the technical and pedagogical groundwork for a new approach to higher education (Bonfield et al. 2020). The global outbreak has speeded up the change, although it may now look very different to previous expectations. Probably, one of the biggest challenges during the COVID-19 confinement was how to motivate the students to develop the attitude necessary to be lifelong learners and not just to have a big score in their exams. Several strategies have been used aimed towards such motivation such as gamification (Brown et al. 2018; Robinson et al. 2018; Efthimiou and Tucker 2020) or the intensive use of images in the forms of illustrations (Goodsell and Jenkinson 2018), movies (Sánchez 2011), or comics (Morel et al. 2019).

Gamification is a participatory form of learning that encourages students to become more focused on a particular topic, which otherwise can be seen as "dry and boring" so, in this way, games can supplement and complement traditional forms of teaching and learning. Games can be used as a tool for promoting collaboration in the classroom, but being such a situation impossible along confinement, digital gaming-based learning (DGBL) has been accessible in its place. There is currently available a variety of digital game formats that can be played through a personal computer or mobile phones, and the projected market growth for "serious games"- games designed entirely for educational purposes - is expected to be $\$ 9.2$ billion by 2023 . Some barriers such as non-standardized frameworks or policies for use or assessment of games and limited amount of time, pedagogical training, and digital literacy of faculty need to be overcome in order to achieve an optimal implementation of a DGBL in the class (Robinson et al. 2018).

Science communication and teaching is dominated by text-based media, although the use of visual tools is increasing over time. The use of images is a much more effective way to translate scientific data into synthetic, clear, and 
Fig. 1 Adaptation of education to the challenges imposed by the coronavirus pandemic. In the pre-pandemic situation, several pedagogical issues (motivation, productivity, attention, creativity, etc.) were addressed using different strategies and tools. At the same time, the use of online educational resources was steadily increasing. The confinement forced the exclusive use of virtual classroom environments, accelerating the process, and at the same time, creating the need for the development of new strategies and tools to cope with the pedagogical issues listed above. Once we defeat the virus, those new methodological approaches boosted by the pandemics will remain, as those that prove successful have definitely come to stay

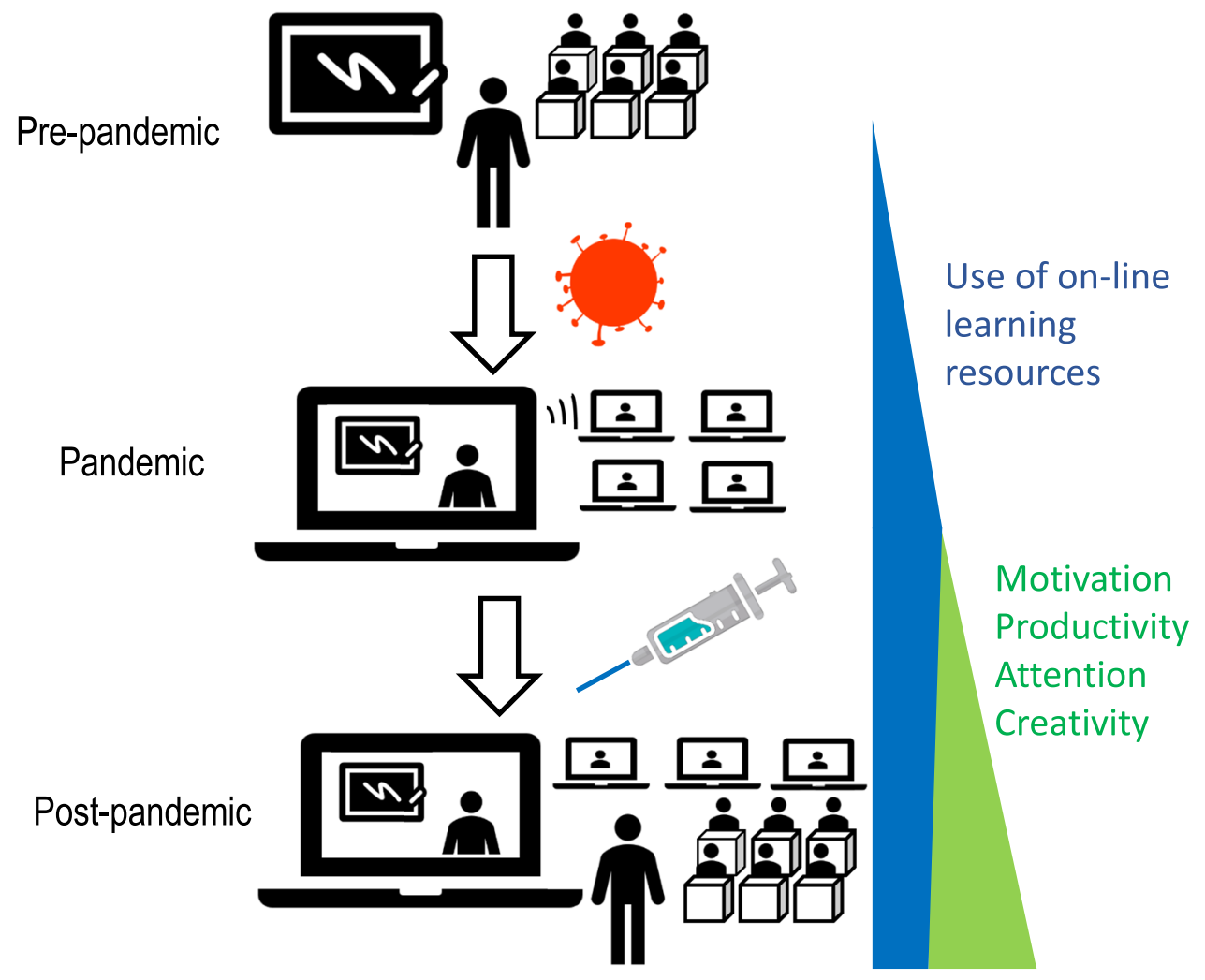

comprehensible information. The internet is a rich reservoir of visual resources that can be used in our classes. But it is also important for educators to be acquainted with some basic rules of design, in order to use visualization as a way to represent scientific concepts and catch the student's attention (Nersesian et al. 2020). The same rules should also be considered when approaching the popularization of science, which requires the development of materials to explain to society complex scientific subjects. The cooperation of professionals skilled in communication, design, and scientific knowledge is the key to success in presenting to the citizen in a straight and simple way scientific or technical issues with a complicated basis.

\section{Conclusion}

The current COVID-19 crisis has offered in itself an actual demonstration that education is the best tool to confront such an unexpected social challenge. During the past years, educators have been wondering about the best methods to train our students in the critical skills needed for a world in continuous change and to be innovative, imaginative, and resilient to change. Suddenly, the lockdowns and social distance imposed by the crisis led us to delve into a rather unsteady situation, which triggered the application of pedagogic methodologies that we had been breeding in the previous years, as a result of the post-Bolonia pedagogic framework and technological advances in digital tools (Fig. 1). Just like microorganisms efficiently evolve to face sudden environmental challenges, academic microbiologists have quickly evolved to proficiently incorporate into their routine digital technologies, the virtual space, and social networks. Through the crisis, we have counted on the advantage of an unprecedented prompting demand from society on biomedical knowledge, especially in the fields of virology, immunology, and biotechnology. Although the challenge has been harsh, the overall results indicate that we were prepared. We had the knowledge, technological support, and, especially, trust and confidence to overcome the situation.

Author contributions M.S.A. led the writing of the body of the article; I.L.G. and V.J.C. contributed to the design, discussion of contents, and revision.

Data availability Not applicable.

\section{Declarations}

Ethics approval and consent to participate Not applicable.

Consent for publication Not applicable. 
Competing interests The authors declare no competing interests.

Authors' information The three authors belong to the Spanish Society for Microbiology Division on Education and Communication of Microbiology.

\section{References}

Antunes et al (2021) MicroMundo@UPorto: an experimental microbiology project fostering student's antimicrobial resistance awareness and personal and social development. FEMS Microbiol Lett 368:fnab016. https://doi.org/10.1093/femsle/fnab016

ASM (2004) Microbiology in the 21st century: where are we and where are we going? Am Soc Microbiol. https://doi.org/10.1128/aamcol. 5sept. 2003

Bonwell C, Eison J (1991) Active learning: creating excitement in the classroom AEHE-ERIC higher education report No. 1. Washington, D.C.: Jossey-Bass. ISBN 978-1-878380-08-1

Bonfield CA, Salter M, Longmuir A, Benson M, Adachi C (2020) Transformation or evolution?: Education 40, teaching and learning in the digital age. High Educ Pedagog 5(1):223-246. https://doi. org/10.1080/23752696.2020.1816847

Brown CL, Comunale MA, Wigdahl B et al (2018) Current climate for digital game-based learning of science in further and higher education. FEMS Microbiol Lett. 365:fny237. https://doi.org/10. 1093/femsle/fny237

de Groot PWJ, Fernández-Pereira J, Sabariegos R, Clemente-Casares P, Parra-Martínez J, Cid VJ, Moreno DA (2019) Optimizing Small World Initiative service learning by focusing on antibiotics-producing actinomycetes from soil. FEMS Microbiol Lett 366:fnaa019. https://doi.org/10.1093/femsle/fnaa019

Efthimiou G, Tucker N (2020) Microbes Against Humanity, a workshop game for horrible students: using a creative card game in higher education microbiology teaching. https://doi.org/10.1099/ acmi.0.000186

Fahnert B (2019) Be prepared - learning for the future. FEMS Microbiol Lett 366:fnz200. https://doi.org/10.1093/femsle/fnz200

Freeman S, Eddy SL, McDonough M, Smith MK, Okoroafor N, Jordt H, Wenderoth MP (2014) Active learning increases student performance in science, engineering, and mathematics. PNAS 111:8410-8415. https://doi.org/10.1073/pnas.1319030111

García AM, Moreno DA (2020) Cursos SEM Formación on-line. SEM@foro 69.22-23

Gewin V (2021) Pandemic burnout is rampant in academia. Nature 591:489-491. https://doi.org/10.1038/d41586-021-00663-2

Grainger R, Liu Q, Geertshuis S (2020) Learning technologies: a medium for the transformation of medical education? Med Educ 55:23-29. https://doi.org/10.1111/medu.14261

Goodsell DS, Jenkinson J (2018) Molecular illustration in research and education. J Mol Biol 430:3969-3981. https://doi.org/10.1016/j. jmb.2018.04.043

Hernandez S, Tsang T, Handelsman J (2015) Small World Initiative: research protocols. Yale University, Connecticut

Hernandez S, Tsang T, Bascom-Slack C et al (2018) Tiny Earth-a research guide to student sourcing antibiotic discovery, 18th edn. XanEdu Publishing Inc., Ann Arbor
Hurley A, et al. (2021) Tiny Earth: a big idea for STEM education and antibiotic discovery. mBio $12 \mathrm{https} / / /$ doi.org/10.1128/mBio. 03432-20

López-Goñi I, Martínez-Viñas MJ, Antón J et al (2017) Twitter as a tool for teaching and communicating microbiology: the \#microMOOCSEM initiative. J Microbiol Biol Educ 17:492-4. https:// doi.org/10.1128/jmbe.v17i3.1200

López-Goñi I, Sánchez-Angulo M (2018) Social networks as a tool for science communication and public engagement: focus on Twitter. FFEMS Microbiol Lett. 365:fnx246. https://doi.org/10.1093/ femsle/fnx 246

López-Goñi I et al (2019) \#EUROmicroMOOC: using Twitter to share trends in Microbiology worldwide. FEMS Microbiol Lett. 366:fnz141. https://doi.org/10.1093/femsle/fnz141

Maicas $S$ et al (2020) Implementation of antibiotic discovery by student crowdsourcing in the Valencian Community through a service learning strategy. Front Microbiol 11:564030. https://doi.org/10. 3389/fmicb.2020.564030

McKenney S, Reeves T (2020) Educational design research: portraying, conducting, and enhancing productive scholarship. Med Educ 55:82-92. https://doi.org/10.1111/medu. 14280

McReynolds MR et al (2020) The art of virtual mentoring in the twenty-first century for STEM majors and beyond. Nat Biotechnol 38:1477-1482. https://doi.org/10.1038/s41587-020-00758-7

Morel M, Peruzzo N, Rodriguez-Juele A, Amarelle V (2019) Comics as an educational resource to teach microbiology in the classroom. J Microbiol Biol Educ. 20: 20.1.26. https://doi.org/10.1128/jmbe. v20i1.1681

Nersesian S, Vitkin N, Grantham S, Bourgaize S (2020) Illustrating your research: design basics for junior clinicians and scientists. BMJ 16:m2254. https://doi.org/10.1136/bmj.m2254

Richardson D (2008) Don't dump the didactic lecture; fix it. Adv Physiol Educ 32:23-24. https://doi.org/10.1152/advan.00048.2007

Robinson LA, Turner IJ, Sweet MJ (2018) The use of gamification in the teaching of disease epidemics and pandemics. FEMS Microbiol Lett. 365:fny111. https://doi.org/10.1093/femsle/fny111

Sánchez M (2011) Bugs and movies: using film to teach microbiology. J Microbiol Biol Educ 12:206-207. https://doi.org/10.1128/jmbe. v12i2.268

Timmis K et al (2019) The urgent need for microbiology literacy in society. Environ Microbiol 21:1513-1528. https://doi.org/10. 1111/1462-2920.14611

Valderrama MJ et al (2018) Educating in antimicrobial resistance awareness: adaptation of the Small World Initiative program to service-learning. FEMS Microbiol Lett. 365:fny 161. https://doi. org/10.1093/femsle/fny 161

Zakrajsek T (2018) Reframing the lecture versus active learning debate: suggestions for a new way forward. Educ Health Prof 1:1-3. https://doi.org/10.4103/EHP.EHP_14_18

Publisher's note Springer Nature remains neutral with regard to jurisdictional claims in published maps and institutional affiliations. 